\title{
Climate driven elevational variation of vascular plants range size in the central Himalayas: a supporting case for Rapoport's rule
}

\author{
Jianchao Liang ${ }^{1}$, Zhifeng Ding ${ }^{1}$, Ganwen Lie $^{2}$, Zhixin Zhou ${ }^{1}$, Paras Singh ${ }^{1}$, Zhixiang \\ Zhang ${ }^{3}$, and Huijian $\mathrm{Hu}^{1}$ \\ ${ }^{1}$ Institute of Zoology,Guangdong Academic of Sciences \\ ${ }^{2}$ Guangdong Eco-Engineering Polytechnic \\ ${ }^{3}$ Beijing Forestry University
}

October 8, 2020

\begin{abstract}
How and why species range size varies along spatial gradients is fundamental yet controversial topics in biogeography. To advance our understanding on these questions and to provide insight into biological conservation, we assessed the elevational variations in vascular plants range size for different life form and biogeographical affinities, and explored the main drivers underlying above variations in the longest valley in China's Himalayas-the Gyirong Valley. Elevational range sizes of vascular plants were documented by 96 sampling plots along 12 elevational bands of 300-m ranging from 1800 to $5400 \mathrm{~m}$ above sea level. We assessed the elevational variations in range size by averaging the range size of all species within each elevational band. We then related range size to climate, disturbance, competition factors and the mid-domain effect, and explored the relative importance of aforementioned factors in explaining the range size variations using the Random Forest model. Total 545 vascular plants were documented by our sampling plots along the elevational gradient. Out of 545 plants, 158, 387, 337 and 112 were woody, herbaceous, temperate and tropical species respectively. Range size of each groups of vascular plants shown uniform increasing trends along the elevational gradient which are in accordance with the prediction of Rapoport's rule. Climate was the main driver for the increasing trends of vascular plants range size in the Gyirong Valley. Climate variability hypothesis and mean climate condition hypothesis were both supported to jointly explain such climate-range size relationship. Our results reinforce previous notion that Rapoport's rule applies to where the influence of climate is most pronounced, and call for close attention to the impact of climate change in order to prevent range contraction and even extinction under global warming.
\end{abstract}

\section{Introduction}

The species range size is a fundamental unit in macroecology (Böhm et al., 2017). Understanding variation of species range size along spatial gradients is of primary importance in study of climate change, biodiversity pattern, gene flow and extinct mechanism. A well-known theory about spatial variation in species range size is the Rapoport's rule, which proposed that species range size correlates positively with latitude and elevation (Stevens, 1989). However, despite of multiple early evidences from the Northern Hemisphere (e.g., Letcher \& Harvey, 1994; Blackburn \& Gaston, 1996; Arita et al., 2005), further study from other regions have found complex and partial support for the rule (e.g., Hawkins et al., 2006; Whitton et al., 2011; Feng et al., 2016), suggesting that the rule might be a regional phenomenon hinge on local environment (Whitton et al., 2011). Therefore, recent attention has shifted from simply documenting variation in range size to exploring drivers for the variation.

Various studies have been conducted to understand the association between variation in range size and 
environment factors such as climate (e.g., Whitton et al., 2011; Sheldon \& Tewksbury, 2014), disturbance (e.g., Lozada et al., 2008; Borkowski et al., 2016), competition (e.g., Glazier \& Eckert, 2002; Grigione et al., 2010), and the mid-domain effect (e.g., Luo et al., 2011). Climate factor is the most widely supported driver in terms of both latitudinal and elevational variation in range size. Several hypotheses have been proposed to explain the climate-range size relationship, among which the climate variability hypothesis is most commonly accepted (Whitton et al., 2011; Pintor et al., 2015). This hypothesis was first proposed by Stevens at 1989, and was believed to be the underlying mechanism of Rapoport's rule (Stevens, 1989,1992). Stevens stated that climate specifically temperature is more variable at higher latitudes and elevations. Such greater climate variability favor species with wider tolerances and larger ranges, and thus leading to a positive relationship between range size and latitude and elevation. The mean climate condition hypothesis is another prominent explanation for climate-range size relationship, which are supposed to cooperate with climate variability to generate increasing trends of range size along latitude and elevation (Luo et al., 2011). The mean climate condition hypothesis proposes that species living at higher latitude or elevation are not only subject to greater climate variation but also lower mean climate condition, and thus tend to be geographically widely distributed (Luo et al., 2011; Jiang \& Ma, 2014). Besides contemporary climate, the historical climate such as Quaternary climate has also been proposed as explanation for range size variations based on the premise that historical climate oscillations select for species with wider physiological tolerance and adaption (Jansson, 2003; Araújo et al., 2008).

Apart from climate factors, disturbance and competition are also considered to have impacts on species range size. The disturbance hypothesis proposes that anthropogenic threats might constrains species distribution due to the consequent population declines and extinctions (Whitton et al., 2011). The competition hypothesis proposes that species in rich communities would face intense competitive pressure which might limit their range size (Stevens, 1996; Gaston et al., 1998). In addition, patterns of range size variation might be subjected to the mid-domain effect (MDE), as large range species necessarily overlap in domain center due to the limit of geometric constraints on species geographical ranges, leading to a mid-domain peak in species range size regardless of ecological factors (Colwell et al., 2004; Moreno et al., 2008).

In addition to environment factors, variations in species range size might also be associated with life-form and biogeographical affinities. This is because, species' life form and biogeographical affinities reflect their ecophysiological traits and evolutionary history, and hence affect their response to environmental variation. For example, compared with herbaceous plants, woody plants tend to have narrower adaptability for their longer reproductive cycles and slower accumulation rate of genetic changes (Smith \& Beaulieu, 2009), and thus might more sensitive to the environmental gradient. Similarly, tropical taxa, which experienced more stable climatic environment in their evolutionary history, may be hence more susceptible to climate variation and were prone to increase their range size to adapt to increasing latitude and elevation (McCain, 2009). However, little work has been done to examine variations in species range size in terms of the influence of life-form and biogeographical affinities (but see Fend et al., 2016 and Zhou et al., 2019).

As one of the world's 34 biodiversity hotspots, the Himalayas contain a diverse range of eco-climate zones, and have been receiving much attention from various ecological and biogeographical studies. Especially in the central Himalayas, where the towering mountains block the moisture from the Indian Ocean, a series of north-south valleys contain rich biodiversity and conspicuous elevational environmental gradient in small spatial scale, making them ideal place for uncovering the underlying mechanisms of the spatial variation in species range size and examining the validity of Rapoport's rule. However, while a number of studies exploring the elevational variation and its drivers for species richness in the Himalayas (e.g., Acharya et al., 2011; Manish et al., 2017; Kluge et al., 2017; Yang et al., 2018; Sun et al., 2020), corresponding studies for species range size are limited. Since understanding range size variations are a prelude to effective biodiversity conservation (Luo et al., 2011), filling up such a research gap will not only help address the theoretical issue but also contribute to the conservation practice in this high-profile region.

Since long, vascular plants have been considered as an excellent matter of study for the spatial variation in range size, because of their wide distribution and easy observation. In this study, we aim to examine 
elevational variations in vascular plants range size for different life form and biogeographical affinities, and to explore the role of climate, disturbance, competition and the mid-domain effect on above variations, based on a detailed field survey in the Gyirong Valley, the longest valley in China's central Himalayas. Since species range size is considered to be closely associated with species richness (Stevens, 1992), and climate has been found to be the primary determinant for species richness in the Himalayas (Bhattarai and Vetaas 2003; Manish et al., 2017; Sun et al., 2020; Liang et al., 2020), we expect that climate factors are also played a greater role than other factors in explaining the elevational variations in vascular plants range size in the Gyirong Valley. If that is the case, considering Rapoport's rule gets supported in regions where the influence of climate is most pronounced (Pintor et al., 2015), we also expect the vascular plants range size increases with elevation as the rule predicted, especially for woody and tropical species which are supposed to be more sensitive to climate variation.

\section{Methods}

\subsection{Study area}

The Gyirong Valley (28 $\left.{ }^{\circ} 16^{\prime}-29 \mathrm{deg} 00^{\prime} \mathrm{N}, 84 \mathrm{deg} 56^{\prime}-85 \mathrm{deg} 24^{\prime} \mathrm{E}\right)$ is located in the southern part of the Tibetan Plateau of China, and border with northern part of Nepal (Fig. 1). The valley is expanded over $90 \mathrm{~km}$, and spans an elevational range from 1,840 to $7,341 \mathrm{~m}$ above sea level (a.s.l.). Due to the influence of the Indian Ocean monsoon, the valley contain steep environmental gradients and distinct elevational vegetation zones which can be divided into evergreen broadleaf forest (1,800-2,500 m a.s.l.), coniferous and broadleaf mixed forest (2,500-3,300 m a.s.l.), subalpine coniferous forest (3,300-3,900 m a.s.l.), alpine bush and coryphilum (3,900-4,700 $\mathrm{m}$ a.s.l.) and alpine tundra with sparse herbs (4,700-5,400 $\mathrm{m}$ a.s.l.). Above 5,400 $\mathrm{m}$ a.s.l. there is the scree and nival zone where very few creatures can survive.

Our study was conducted along an elevation gradient from Resuo village at 1,800 m a.s.l. to Mt. Kongtanglamu and Mt. Mala at 5,400 m a.s.l.. We divided the gradient into 12 elevational bands of 300-m. Elevation lower than $1800 \mathrm{~m}$ a.s.l. and high than $5400 \mathrm{~m}$ a.s.l. were excluded from the study due to the geopolitical restrictions and scree and nival zone where very few creatures can survive.

\subsection{Species sampling}

Field study was carried out by 96 sampling plots along the 12 elevational bands from 1800 to $5400 \mathrm{~m}$ a.s.l. in July and August 2018. For each band, 8 sampling plots were placed depending upon the most common physiognomic vegetation and the topographic accessibility. In each plot, the vascular plant inventories were conducted exhaustively (2-4 hours by 5 persons) with a quadrat of $400 \mathrm{~m}^{2}$ following Fang et al. (2009). Species that could not be identified in the field were taken to the Museum of Beijing Forestry University for identification.

\subsection{Species grouping}

To assess the influence of life form and biogeographical affinities on range size variation, we classified the vascular plants into four groups: (1) woody species, including trees and shrubs, (2) herbaceous species, including herbs and climber, (3) temperate species, whose distribution centers located in north temperate regions, and (4) tropical species, whose distribution centers located in pantropic regions. Life form and biogeographical affinities were determined referring to Flora of China (www.efloras.org), Flora of Pan-Himalayas (www.flph.org), Flora Xizangica (Wu, 1983) and Floristics of Seed Plants from China (Wu et al., 2010). 


\subsection{Species range size}

For each species, elevational range size was estimated as the difference between maximum and minimum elevational band that it occurred. Following Steven's method (Steven, 1992), we average species range size for all groups of vascular plants within each elevational band.

\subsection{Environmental variables}

Ten environmental variables which were divide into six groups were used to examine the role of mean climate condition, climate variability, historical climate change, disturbance, competition and the mid-domain effect on the elevational variation in vascular plants range size.

The mean climate condition variables include annual temperature (MAT) and mean annual precipitation (MAP). The climate variability variables include temperature seasonality (TS) and annual temperature range (MATR). MAT, MAP, TS, and MATR were derived from six mini weather stations establishing along the Gyirong Valley from 2016 to 2018 (2,457, 2,792, 3,368, 3,740, 4,140, and 5,230 m a.s.l., Fig. 1). We averaged three years' data of the four variables for each station and extrapolated them for the entire study area using Kriging interpolation in a GIS environment (Hu et al., 2018), and then used the average of 8 grid cells corresponding to the sampling plots at each elevational band.

The variables of historical climate change included change in mean annual temperature (TC) and precipitation (PC) between present and the Last Glacial Maximum (LGM, about 22,000 years ago). The annual temperature and precipitation of the LGM were derived from the average of three Global Climate Models (GCMs), namely, CCSM4, MIROC-ESM, and MPI-ESM-P, which were obtained from the WorldClim dataset (www.worldclim.org).

Variables related disturbance factors included the population (POP) and area of anthropogenic land use (AALU). The POP data was provided by the authority of Mount Qomolangma National Nature Reserve. The AALU was calculated as the area of artificial surfaces and cultivated land (Zhang et al., 2013) extracted from the GlobeLand30 land cover data (http://www.globallandcover.com).

Since the direct measurement of competition is difficult to achieve, we used the interpolated species richness as an indirect reflection (Stevens, 1996). The MDE were tested using the predicted average range size under geometric constraints, which were computed by randomizing the empirical species range size within the bounded domain using 1000 Monte Carlo simulations in the modules Mid-Domain Null (MaCain, 2004; Luo et al., 2011).

\subsection{Statistical analysis}

For each elevational band, we calculated the species accumulation curve to assess the sampling adequacy. Sampling in a band was considered adequate when the species accumulation curve reaches a plateau (Magurran and McGill, 2011). Additionally, we computed non-parametric estimated species richness (Chao2 and Jackknife2) for each band, and then performed regression of the observed species richness against the nonparametric estimated species richness (Colwell \& Coddington, 1994; Rowe, 2009).

Linear regressions were calculated to assess the relationship between elevation and range size for all groups of vascular plants. Rapoport's rule is supported where the relationship is positive (Moreno et al., 2008).

Relationships between species range size and elevation and each environmental variable were assessed using ordinary least squares (OLS) models. Simultaneous autoregressive (SAR) model was also performed in supplement to take account for the spatial autocorrelation in variables. All variables were standardized (mean $=0$ and standard deviation $=1)$ to make the regression coefficients comparable in OLS and SAR.

Random Forests model was used to explore the relative importance of each environmental variable in explaining the range size variations for each species group. We chose the Random Forests model because it does not 
require strict assumptions in data and can better handle multicollinearity and non-linear relationships which perplexed most traditional methods like GLMs (Breiman, 2001; Feng et al., 2016). We run the Random Forests model 1000 times, and assessed the relative importance of each environmental variable based on the average of the percentage increase in mean squared error (\%IncMSE) from the models. The \%IncMSE was calculated by repeated permutation of each regression variable, which represents the increase in prediction error caused by each individual variable.

Species accumulation curve and estimated species richness were calculated by EstimateS 9.10 (Colwell, 2013). linear regression, OLS, SAR, and the Random Forest models as well as the bivariate model were conducted in R 3.5.1 using vegan, spdep, and randomForest package.

\section{Results}

\subsection{Sampling effort}

Total 545 vascular plants belonging to 106 families and 339 genera were recorded from 96 sampling plots along the elevational gradient in the Gyirong Valley. Out of all the vascular plants, 158 were woody $(28.99 \%)$ and 387 were herbaceous (71.01\%), 337 were temperate $(61.83 \%)$ and 112 were tropical (20.55\%) species. For each of 300-m elevational band, the species accumulation curves reached plateau (Fig. 2), and the non-parametric estimated species richness were highly correlated with the observed species richness (Choa2, $\mathrm{R}^{2}=0.974, p$ $<0.01$; Jackknife2, $\mathrm{R}^{2}=0.988, p<0.01$; Table $\mathrm{S} 2$ ), suggesting that the sampling effort was adequate.

\subsection{Elevational trends of species range size and environmental variables}

For all groups of vascular plants, species range size correlated positively with elevation $\left(\beta_{i} 0.7, p<0.01\right)$, and shown uniform increasing trends along the elevational gradient as predicted by Rapoport's rule (Fig. 3). Woody species and tropical species were found having relatively stronger range size-elevation relationship with higher regression coefficient.

With increasing elevation, MAT and MAP decreased steeply whereas MATR and TS increased monotonically, TC and PC showed a similar pattern which generally decreased with an intermediate trough at $2400 \mathrm{~m}$ a.s.l., POP and AALU showed a similar bimodal pattern with peaks at 2700 and $4200 \mathrm{~m}$ a.s.l. corresponding to the Gyirong town and Zongga town, SR showed a left-skewed hump-shaped pattern with peak at $3000 \mathrm{~m}$ a.s.l. (Fig. 4). MDE of all groups of vascular plants showed a mid-peak pattern (Fig. 4, Fig. S1).

\subsection{Relationship between species range size and environmental variables}

OLS models and SAR models showed similar results about the relationship between species range size and environmental variables, though the correlation would decrease when the spatial autocorrelation was taken into account (Table 1). For all groups of vascular plants, almost all environmental variables were significantly correlated with species range size along the elevational gradient, except for MDE, POP, and AALU. Among them, MAT, MAP, TC, PC, and SR showed negative relationship with species range size, whereas MATR and TS showed positive relationship with species range size.

\subsection{Relative importance of each environmental variables}

The Random Forest models explained 58.09\%, 60.24\%, 51.86\%, 52.05\%, and $41.93 \%$ of the variation of range size in overall species, woody species, herbaceous species, temperate species, and tropical species, respectively. Generally, MATR, TS, MAT and MAP are the most important variables in explaining the elevational variation of range size across all groups of vascular plants (Fig. 5). SR, TC, and PC also play 
supplementary roles in determining the range size of vascular plants, whereas MDE, POP, and AALU appear to be weak explanations of range size.

\section{Discussion}

The range size of all groups of vascular plants shown uniform increasing trends along the elevational gradient of the Gyirong Valley. As our prediction, climate factors did play a greater role than other factors in shaping above trends. Both of the climate variability hypothesis and the mean climate condition hypothesis were supported to explain such climate-range size relationship. Therefore, it is not surprising that Rapoport's rule was supported regardless of life form and biogeographical affinities.

\subsection{The influence of life form and biogeographical affinities}

Life form and biogeographical affinities have been considered to cause differences in the response of species to environmental gradient, but studies about how they influence the elevational variations in species range size are relatively scarce (but see Feng et al., 2016 and Zhou et al., 2019). In Mount Kenya, Zhou et al. (2018) observed a monotonic increasing trend for herbaceous species but an obvious right skewed unimodal trend for woody species, whereas in Nepal, Feng et al. (2016) reported that the tropical species shown partial support for Rapoport's rule, while temperate species opposed the rule. However, in the Gyirong Valley of the central Himalayas, range size of vascular plants across different life form and biogeographical affinities showed uniform increasing trends, though woody species and tropical species did have relatively stronger range sizeelevation relationship as they are supposed to be more sensitive to environmental gradient. Zhou et al. (2018) attributed the decrease of woody species range size at the higher elevation of Mount Kenya to higher proportion of endemic species. But in the Gyirong Valley, both richness and proportion of endemic species shown a left skewed unimodal pattern (Fig. S2), higher elevation was characterized by widely distributed nonendemic species such asSpiraea alpine, Potentilla parvifolia, Lonicera spinosa, which might account for above difference in elevational trends of woody species range size. On the other hand, it must be noted that none of the climatic variability variables in Nepal shown increase trends with elevation (Feng et al., 2016), whereas all climatic variability variables in the Gyirong Valley increased monotonically along elevational gradient. Given that the increasing climatic variability gradient is indispensable for Rapoport's rule, it's thus the rule got equivocal supported in Feng's study but got strong supported in our study. Taken together, we have reasons to contend that the influence of life form and biogeographical affinities on the range size variation may be context-dependent.

\subsection{The role of different environmental factors}

Climate, especially contemporary climate, played a greater role than other environmental factors in shaping the increasing trends of vascular plants range size in the Gyirong Valley. This result echo the predominance of climate in determining elevational gradient of plants richness in the Himalayas (Bhattarai and Vetaas 2003; Manish et al., 2017; Sun et al., 2020; Liang et al., 2020), which could be attribute to the fact that the Himalayas have a more distinct and complete vertical climatic gradient compare to that of most mountains at the same latitude due to its unparalleled elevational range. For example, all contemporary climate variables including MAT, MAP, TS, and MATR shown monotonic trends along the elevational gradient in the Gyirong Valley. TS and MATR are the most important variables for range size of all groups of vascular plants and showed significant positive relationship with range size. Higher elevations where climate is more variable did indeed harbor more large range species, which provide a supporting evidence for the climate variability hypothesis. In addition, the mean climate condition hypothesis was also supported as MAT and MAP shown great importance and significant negative relationship with range size, suggesting that the impacts of climate variability and mean climate condition on range size variation are inseparable. 
Beyond the primary importance of contemporary climate, competition and historical climate also play supplementary roles in shaping the elevational trends of range size. Competition could constrain species dispersal (Jiang \& Ma, 2014). Species in communities with high species richness tend to have narrow distribution, and vice versa (Jiang \& Ma, 2014). Thus, it is not surprising that species range size was correlated negatively with SR along the elevational gradient in the Gyirong Valley. What's surprising is that, species range size also showed negative relationships with TC and PC. It is possible that historical climate oscillations could promote speciation (Hewitt, 1996, 2004; Leprieur et al., 2011; Zhao et al., 2016), resulting in higher proportion of narrowly distributed endemic species at the lower elevations of the Gyirong Valley.

Disturbance factors and MDE pose minimal contribution to the elevational variation in range size. Since the Gyirong Valley is located within the Mount Qomolangma National Nature Reserve (Fig. 1), human activities are restricted in the vicinity of Gyirong town and Zongga town, and hence has less impact on the distribution of vascular plants. The influence of the MDE was affected by the range size of species, species with large range are more sensitive to MDE (Colwell et al., 2004). In the Gyirong Valley, over $90 \%$ of the vascular plant has small range less than $1800 \mathrm{~m}$ (half of the sampling gradient), which could account for weak explanation power of MDE.

\subsection{The applicability of Rapoport' rule}

Since its formulation, the validity of Rapoport's rule has been controversial. The applicability of the rule varies greatly in different region around the world. In general, the rule appears to be more well-defined in Northern Hemisphere and higher latitude than in Southern Hemisphere and lower latitude (Böhm et al., 2017). It is important to remember that, when Stevens first introduced the Rapoport's rule in 1989, he emphasized the rule should apply to species that live in regions with conspicuous gradient of climate variability (Stevens 1989). Further studies have been also confirmed the necessity of climate variability to the validity of Rapoport's rule. For example, Whitton (2011) suggested that the primary importance of climate variability may explain why Rapoport's rule is largely restricted to northern latitudes, as this is where temperature seasonality is most pronounced. Similarly, Pintor et al. (2015) attributed the absence of Rapoport's rule in Australia to the complex climate pattern across the whole continent with minimum and maximum temperatures varying considerably at any given latitude. In our study, climate variability showed monotonical increasing pattern along the elevational gradient in Gyirong Valley, and was the most influential factor behind the elevational variation in range size of all groups of vascular plants. Therefore, it's not surprising that Rapoport's rule was supported regardless of life form and biogeographical affinities. Our results challenge previous argument that life form and biogeographical affinities may influence the applicability of Rapoport' rule, and support that climate variability are the ultimate determinant for the validity of Rapoport's rule.

\subsection{Conservation implication}

Since climate plays a large role in determining species range, there is urgent need to keep eyes on the impact of climate change. It has been widely reported that climate change will force species to shift their distribution upward in mountains (Feeley et al., 2010, 2011; Rehm, 2014), and lead to the movement of elevational biodiversity hotspot (Wu et al., 2016). On the other hand, climate change has been also implicated in species range contractions at many mountains. For example, Engler et al. (2011) assess the impacts of climate change on 2632 plant species across all major European mountain ranges, and found that $36-55 \%$ of alpine species, $31-51 \%$ of subalpine species and 19-46\% of montane species lose more than $80 \%$ of their suitable habitat by 2070-2100. Since the Himalayas are among the most sensitive region to climate change (Xu et al., 2009), we have reasons for concerns about the susceptibility and adaption of plants to the impact of climate change. Specifically, given the extreme environmental condition and geographic constraints at the high elevation of the Gyirong Valley, plants might fail to expand their upper limit while their lower range limit rise with their upward range shift under climate change, leading to range contraction, and even extinction of narrow range 
species. Considering the response to climate change are species-specific, therefore, long-term monitoring is imperative for understanding the impact of climate change on local biodiversity.

\section{Conclusions}

In the Gyirong Valley of the central Himalayas, range size of vascular plants across different life form and biogeographical affinities were found increasing uniformly along the elevational gradient, which were in accordance with the prediction of Rapoport's rule. Climate, especially contemporary climate, was the main driver for the increasing trends of vascular plants range. Both the climate variability hypothesis and the mean climate condition hypothesis were supported in explaining the elevational variation of range size. Our results reinforce previous notion that Rapoport's rule applies to where the influence of climate is most pronounced. Such a climate-driven variations of range size call for close attention to the impact of climate change, which has been implicated in range contractions and even extinction of many taxa.

\section{Acknowledgements}

This study was supported by the National Natural Science Foundation of China (No. 31400361, No. 31901220), the Training Fund of Guangdong Institute of Applied Biological Resources for PhDs, Masters and Postdoctoral Researchers (GIABR-pyjj201703), the GDAS' Project of Science and Technology Development (2019GDASYL-0105044), the Biodiversity Survey and Assessment Project of the Ministry of Ecology and Environment, China (2019HJ2096001006) and the GDAS' Special Project of Science and Technology Development (2018GDASCX-0107).

\section{Author Contributions}

J. Liang, Z. Zhang and H. Hu conceived and designed the study. J. Liang, Z. Ding, G, Lie and Z. Zhou performed the field survey. J. Liang, Z. Ding and Z. Zhou analyzed the data. J. Liang, Z. Ding and P.B. Singh wrote the paper. All authors reviewed drafts of the paper and agreed on the main conclusions of the manuscript.

\section{Data Accessibility}

Data are provided as Supporting Information Table S1.

\section{References}

Acharya, B.K., Chettri, B., \& Vijayan, L., (2011). Distribution pattern of trees along an elevation gradient of Eastern Himalaya, India. Acta Oecol, 37 (4), 329-336.

Araújo, M.B., Nogués-Bravo, D., Diniz-Filho, J.A.F., Haywood, A.M., Valdes, P.J., \& Rahbek, C., (2008). Quaternary climate changes explain diversity among reptiles and amphibians. Ecography, 31 (1), 8-15.

Arita, H.T., Rodrı'guez, P., \& Va'zquez-Domı'nguez, E., (2005). Continental and regional ranges of North American mammals: Rapoport's rule in real and null worlds. Journal of Biogeography, 32 (6), 961-971.

Bhattarai, K.R., \& Vetaas. O.R., (2003). Variation in plant species richness of different life forms along a subtropical elevation gradient in the Himalayas, east Nepal. Global Ecology and Biogeogr, 12 (4), 327-340. 
Blackburn, T.M., \& Gaston, K.J., (1996). Spatial Patterns in the Geographic Range Sizes of Bird Species in the New World. Philosophical Transactions of the Royal Society B: Biological Sciences, 351 (1342), 897-912.

Böhm, M., Kemp, R., Williams, R., Davidson, A. D., Garcia, Andrés, Mcmillan, K. M., .. \& Collen, B., (2017). Rapoport's rule and determinants of species range size in snakes. Diversity and Distribution, 23 (12), 1472-1481.

Borkowski, J., Ukalska, J., Jurkiewicz, J., \& Chećko, E., (2016). Living on the boundary of a post-disturbance forest area: The negative influence of security cover on red deer home range size. Forest Ecology and Management, 381, 247-257.

Breiman, L., (2001). Random forests. Machine Learning, 45 (1), 5-32.

Chan, W.P., Chen, I.C., Colwell, R.K., Liu, W.C., Huang, C.Y., \& Shen, S.F., (2016). Seasonal and daily climate variation have opposite effects on species elevational range size. Science, 351 (6280), 1437-1439.

Colwell, R.K., \& Coddington, J.A., (1994). Estimating terrestrial biodiversity through extrapolation.Philosophical transactions of the Royal Society of London. Series B, Biological sciences, 345(1311), 101-118.

Colwell, R.K., Rahbek, C., \& Gotelli, N.J., (2004). The mid-domain effect and species richness patterns: what have we learned so far? The American Naturalist, 163 (3), E1-E23.

Engler, R., Randin, C., Thuiller, W., Dullinger, S., Zimmermann, N.E., Araújo, M.B., .. \& Guisan, A., (2011). 21st century climate change threatens mountain flora unequally across Europe. Global Change Biology, 17 (7), 2330-2341.

Fang, J., Wang, X., Shen, Z., Tang, Z., He, J., Yu, D., .. \& Guo, Z., (2009). Methods and protocols for plant community inventory. Biodiversity Science, 17 (6), 533-548.

Feng, G., Mao, L., Sandel, B., Swenson, N.G., \& Svenning, J., (2016). High plant endemism in China is partially linked to reduced glacial-interglacial climate change. Journal of Biogeography, 43 (1), 145-154.

Feng, J., Hu, X., Wang, J., \& Wang, Y., (2016). Support for the elevational Rapoport's rule among seed plants in Nepal depends on biogeographical affinities and boundary effects. Ecology and Evolution, 6 (20), 7246-7252.

Feeley, K.J., \& Silman, M.R., (2010). Land-use and climate change effects on population size and extinction risk of Andean plants. Global Change Biology, 16 (12), 3215-3222.

Feeley, K.J., Silman, M.R., Bush, M.B., Farfan, W., Cabrera, K.G., Malhi, Y., .. \& Sassan, S., (2011). Upslope migration of Andean trees. Journal of Biogeography, 38 (4), 783-791.

Gaston, K.J., Blackburn, T.M., \& Spicer, J.I., (1998). Rapoport's rule: time for an epitaph? Trends in Ecology Evology \& Evolution, 13 (2), 70.

Glazier, D.S., \& Eckert, S.E., (2002). Competitive ability, body size and geographical range size in small mammals. Journal of Biogeography, 29(1), 81-92.

Grigione, M.M., Beier, P., Hopkins, R.A., Neal, D., Padley, W.D., Schonewald, C.M., \& Johnson, M.L., (2010). Ecological and allometric determinants of home-range size for mountain lions (Puma concolor). Animal Conservation, 5(4), 317-324.

Hawkins, B.A, \& Diniz-Filho, J.A.F., (2006). Beyond Rapoport's rule: evaluating range size patterns of New World birds in a two-dimensional framework. Global Ecology and Biogeography, 15 (5), 461-469.

Hewitt, G.M., (1996). Some genetic consequences of ice ages, and their role, in divergence and speciation. Biological Journal of the Linnean Society, 58 (3), 247-276. 
Hewitt, G.M., (2004). Genetic consequences of climatic oscillations in the Quaternary. Philos. Philosophical Transactions of the Royal Society B: Biological Sciences, 359 (1442), 183-195.

Hu, Y., Ding, Z., Jiang, Z., Quan, Z., Guo, Q., Tian, K., .. \& Luke Gibson. (2018). Birds in the himalayas: what drives beta diversity patterns along an elevational gradient? Ecology and Evolution, 8 (23), 11704-11716.

Kerr, J.T., Pindar, A., Galpern, P., Packer, L., Potts, S.G., Roberts, S.M., .. \& \& Pantoja, A., (2015). Climate change impacts on bumblebees converge across continents. Science, 349 (6244), 177-80.

Kluge, J., Worm, S., Lange, S., Long, D., Bohner, J., Yangzom, R., .. \& \& Miehe, G., (2017). Elevational seed plants richness patterns in bhutan, eastern himalaya. Journal of Biogeography, 44 (8), 1711-1722.

Leprieur, F., Tedesco, P.A., Hugueny, B., Beauchard, O., Durr, H.H., Brosse, S., .. \& \& Thierry, O., (2011). Partitioning global patterns of freshwater fish beta diversity reveals contrasting signatures of past climate changes. Ecology letters, 14 (4), 325-334.

Letcher, A.J., \& Harvey, P.H., (1994). Variation in Geographical Range Size Among Mammals of the Palearctic. The American Naturalist, 144 (1), 30-42.

Liang, J., Ding, Z., Lie, G., Zhou, Z., Singh, P.B., \& Zhang, Z., (2020). Species richness patterns of vascular plants and their drivers along an elevational gradient in the central Himalayas. Global Ecology and Conservation, in press.

Lozada, T., Koning, G.H.J.D., Kessler, M., Klein, A., \& Tscharntke, T., (2008). Geographical range size of tropical plants influences their response to anthropogenic activities. Diversity and Distributions, 14 (1), $59-68$.

Luo, Z.H., Tang, S.H., Li, C.W., Chen, J., Fang, H.X., \& Jiang, Z.G., (2011). Do Rapoport's Rule, MidDomain Effect or Environmental Factors Predict Latitudinal Range Size Patterns of Terrestrial Mammals in China? Plos One, 6 (11), e27975.

Jiang Z.G., \& Ma K.P., (2014). The Principles of Conservation Biology. Science Press, Beijing.

Magurran, A.E., \& McGill, B.J., (2011). Biological Diversity: Frontiers in Measurement and Assessment. Oxford University Press, Oxford, UK.

Manish, K., Pandit, M.K., Telwala, Y., Nautiyal, D.C., Koh, L.P., \& Tiwari, S., (2017). Elevational plant species richness patterns and their drivers across non-endemics, endemics and growth forms in the eastern himalaya. Journal of plant research, 130(5), 829-844.

Mccain, C.M., (2004). The mid-domain effect applied to elevational gradients: species richness of small mammals in Costa Rica. Journal of Biogeography, 31 (1), 19-31.

McCain, C.M., (2009). Vertebrate range sizes indicate that mountains may be "higher" in the tropics. Ecology Letter, 12 (6), 550-560.

Moreno, R.A., Rivadeneira, M.M., Hernandez, C.E., Sampertegui, S., \& Rozbaczylo, N., (2010). Do Rapoport's rule, the mid-domain effect or the source-sink hypotheses predict bathymetric patterns of polychaete richness on the Pacific coast of South America? Global Ecology and Biogeography, 17 (3), 415-423.

Pintor, A.F.V., Schwarzkopf, L., \& Krockenberger, A.K., (2015). Rapoport's Rule: Do climatic variability gradients shape range extent? Ecological Monographs, 85 (4), 643-659.

Rehm, E.M., (2014). Rates of upslope shifts for tropical species depend on life history and dispersal mode. Proceedings of the National Academy of Sciences of the United States of America, 111, E1676.

Roland, J., (2003). Global patterns in endemism explained by past climatic change. Proceedings of the Royal Society B: Biological Sciences, 270 (1515), 583-590. 
Rowe, R.J., (2009). Environmental and geometric drivers of small mammal diversity along elevational gradients in Utah. Ecography, 32 (3), 411-422.

Sheldon, K.S., \& Tewksbury, J.J., (2014). The impact of seasonality in temperature on thermal tolerance and elevational range size. Ecology, 95 (8), 2134-2143.

Smith, S.A., \& Beaulieu, J.M., (2009). Life history influences rates of climatic niche evolution in flowering plants. Proceedings of the Royal Society B, 276 (1677), 4345-4352.

Stevens, G.C., (1989). The Latitudinal Gradient in Geographical Range: How so Many Species Coexist in the Tropics. The American Naturalist, 133 (2), 240-256.

Stevens, G. C., (1996). Extending Rapoport's rule to pacific marine fishes. Journal of Biogeography, 23 (2), $149-154$.

Stevens, G.C., (1992). The Elevational Gradient in Altitudinal Range: An Extension of Rapoport's Latitudinal Rule to Altitude. The American naturalist, 140 (6), 893-911.

Sun, L., Luo, J., Qian, L., Deng, T., \& Sun, H., (2020). The relationship between elevation and seedplant species richness in the Mt. Namjagbarwa region (Eastern Himalayas) and its underlying determinants. Global Ecology and Conservation, 23, e01053.

Whitton, F.J.S., Purvis, A., Orme, C.D.L., \& Olalla-Tarraga, M.A., (2012). Understanding global patterns in amphibian geographic range size: does Rapoport rule? Global Ecology and Biogeography, 21 (2), 179-190.

Wu, Y., DuBay, S.G., Colwell, R.K., Ran, J., \& Lei, F., (2016). Mobile hotspots and refugia of avian diversity in the mountains of south-west China under past and contemporary global climate change. Journal of Biogeography, 44 (3), 615-626.

Wu, Z., Sun, H., Zhou, Z., Li, D., \& Peng, H., (2010). Floristics of Seed Plants from China. Science Press, Beijing.

Xu, J., Grumbine, R.E., Shrestha, A.B., Eriksson, M., Yang, X., Wang, Y., \& Wilkes, A., (2009). The melting Himalayas: cascading effects of climate change on water, biodiversity, and livelihoods. Conservation Biology, 23 (3),520-530.

Yang, M., Lu, Z., Fan, Z., Liu, X., Hens, L., Wulf, R.D., \& Ou, X., (2018). Distribution of non-native plant species along elevation gradients in a protected area in the eastern Himalayas, China. Alpine Botany, 128 (2), 169-178.

Zhang, J., Kissling, W.D., \& He, F., (2013). Local forest structure, climate and human disturbance determine regional distribution of boreal bird species richness in Alberta, Canada. Journal of Biogeography, 40 (6), 1131-1142.

Zhao, J., Gugger, P.F., Xia, Y., \& Li, Q., (2016). Ecological divergence of two closely related Roscoea species associated with late quaternary climate change. Journal of Biogeography, 43 (10), 1990-2001.

Zhou, Y., Ochola, A.C., Njogu, A.W., Boru, B.H., Mwachala, G., Hu, G., .. Wang, Q., (2020). The species richness pattern of vascular plants along a tropical elevational gradient and the test of elevational Rapoport's rule depend on different life-forms and phytogeographic affinities. Ecology and Evolution,l 9 (8), 4495-4503.

\section{Tables}

Table 1 The ordinary least squares (OLS) models for each environmental variable and species range size of all group of vascular plants. Coefficients (coef) were given as a measure of the strength of the correlation. 


\begin{tabular}{|c|c|c|c|c|c|c|}
\hline & Overall species & Overall species & Woody species & Woody species & Herbaceous species & Herbaceous species \\
\hline & Overall species & Overall species & Woody species & Woody species & Herbaceous species & Herbaceous species \\
\hline & Coef $_{\text {OLS }}$ & Coef $_{\text {SAR }}$ & Coef $_{\text {OLS }}$ & Coef $_{\text {SAR }}$ & Coef $_{\text {OLS }}$ & Coef $_{\text {SAR }}$ \\
\hline MAT & $-0.853^{* * *}$ & $-0.594^{* * *}$ & $-0.941^{* * *}$ & $-0.815^{* * *}$ & $-0.775^{* *}$ & $-0.523^{* *}$ \\
\hline MAP & $-0.913^{* * *}$ & $-0.742^{* * *}$ & $-0.922^{* * *}$ & $-0.550^{* * *}$ & $-0.857^{* * *}$ & $-0.674^{* * *}$ \\
\hline TS & $0.810^{* *}$ & $0.524^{* *}$ & $0.935^{* * *}$ & $0.863^{* * *}$ & $0.722^{* *}$ & $0.457^{* *}$ \\
\hline MATR & $0.830^{* * *}$ & $0.556^{* * *}$ & $0.940^{* * *}$ & $0.853^{* * *}$ & $0.747^{* *}$ & $0.486^{* *}$ \\
\hline MDE & 0.344 & 0.341 & 0.074 & 0.045 & 0.438 & 0.425 \\
\hline $\mathrm{TC}$ & $-0.723^{* *}$ & $-0.489^{* *}$ & $-0.911^{* * *}$ & $-0.464^{* * *}$ & $-0.633^{*}$ & $-0.455^{*}$ \\
\hline $\mathrm{PC}$ & $-0.693^{*}$ & $-0.340^{*}$ & $-0.863^{* * *}$ & $-0.358^{* * *}$ & $-0.588^{*}$ & $-0.300^{*}$ \\
\hline POP & 0.341 & 0.251 & 0.083 & 0.037 & 0.436 & 0.321 \\
\hline AALU & 0.356 & 0.236 & 0.078 & 0.073 & 0.445 & 0.308 \\
\hline SR & $-0.681^{*}$ & $-0.312^{*}$ & $-0.835^{* * *}$ & $-0.525^{* * *}$ & $-0.568^{*}$ & $-0.240^{*}$ \\
\hline
\end{tabular}

${ }^{*} \mathrm{P}<0.05,{ }^{* *} \mathrm{P}<0.01,{ }^{* * *} \mathrm{P}<0.001$.

\section{Figures}

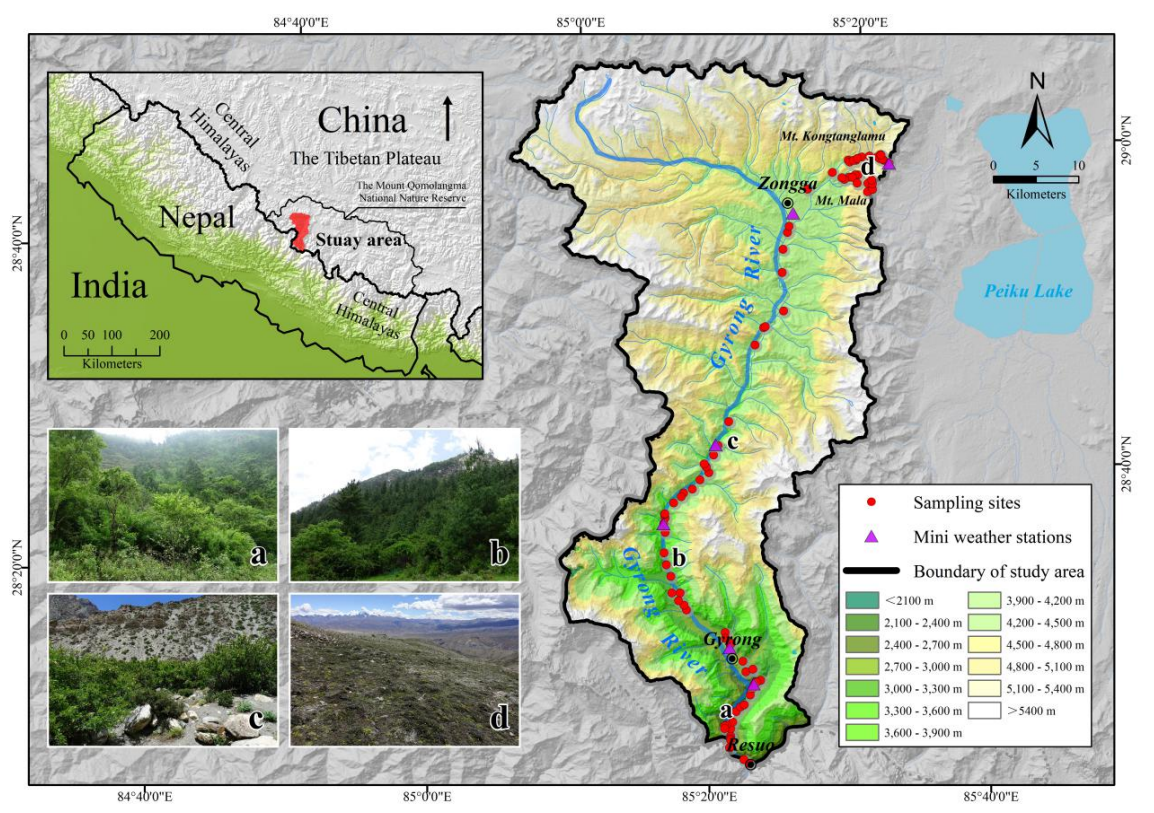

Fig. 1 Map of the study area showing the 96 sampling sites and the 6 mini weather stations along the Gyirong Valley. The letters correspond to the vegetation zones showing in the lower left corner of the map: (a) evergreen broadleaf forest; (b) subalpine coniferous forest; (c) alpine bush and coryphilum; (d) alpine tundra with sparse herbs. 


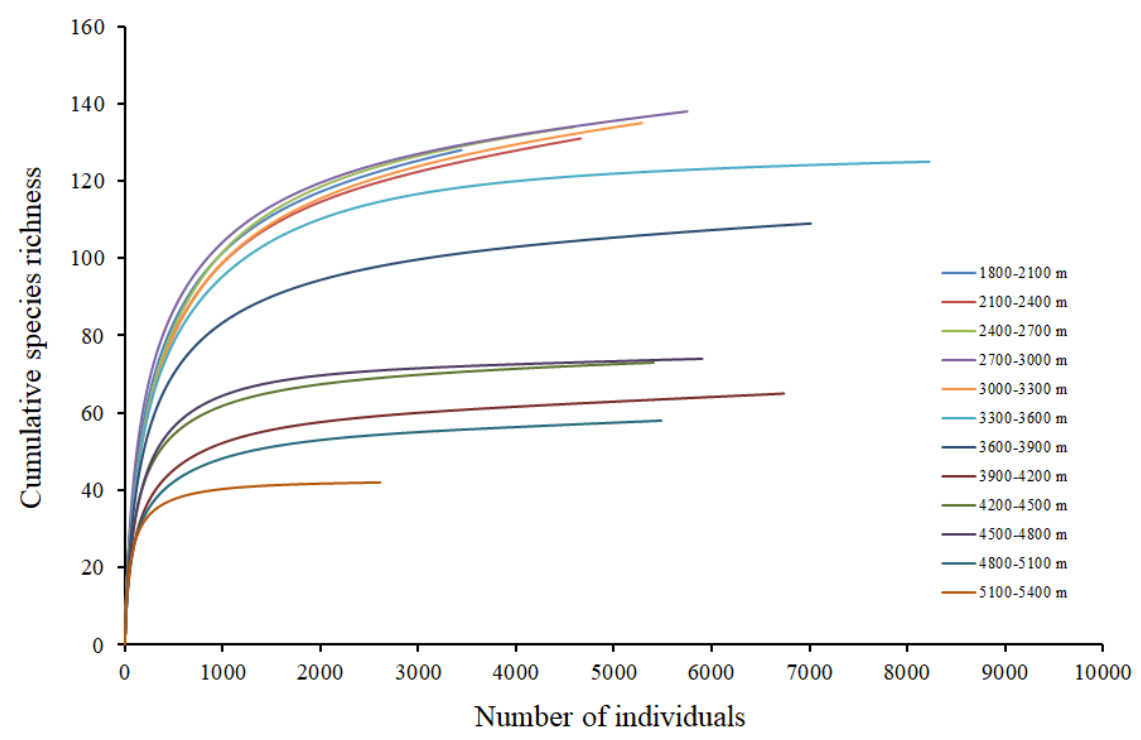

Fig. 2 Species accumulation curves for each 300-m elevational band in the Gyirong Valley.
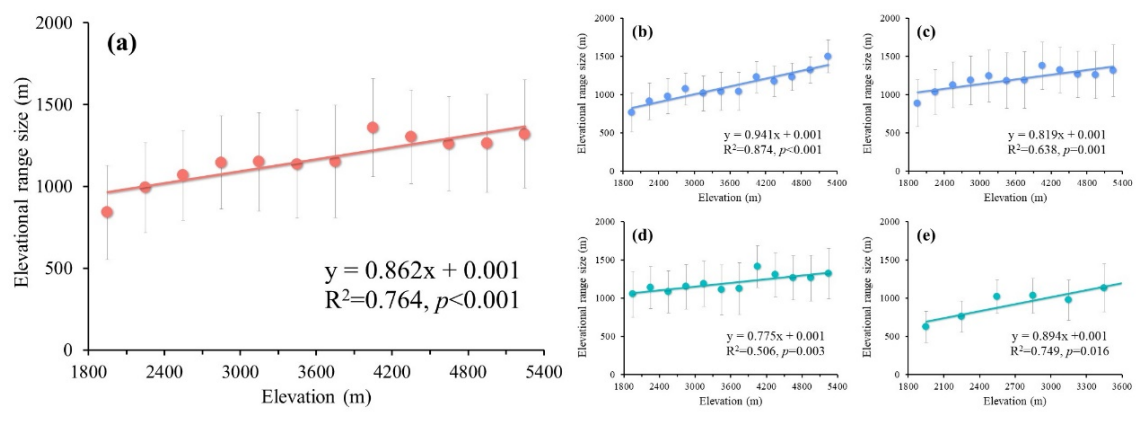

Fig. 3 Elevational trends of range size of (a) overall species, (b) woody species, (c) herbaceous species, (d) temperate species, and (e) tropical species in the Gyirong Valley.
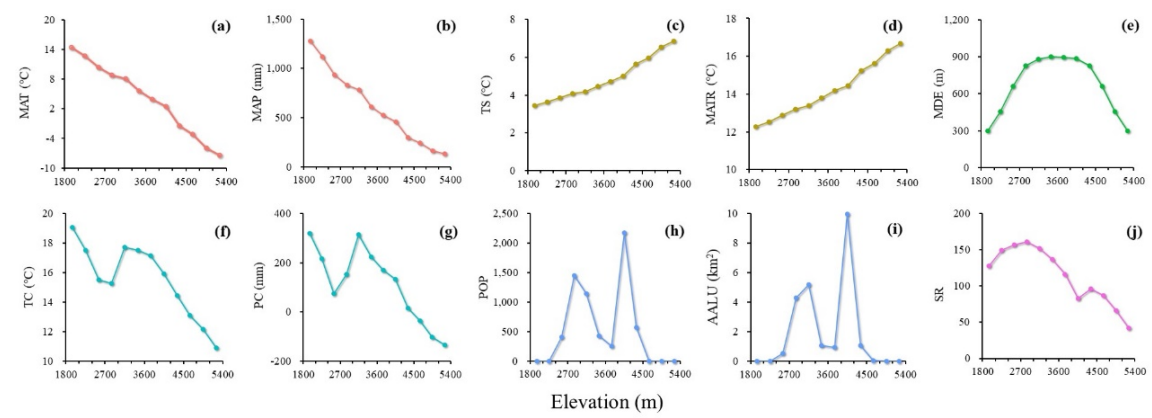

Fig. 4 Elevational variations of (a) mean annual temperature, MAT; (b) mean annual precipitation, MAP; (c) temperature seasonality, TS; (d) mean annual temperature range, MATR; (e) mid-domain effect, MDE; (f) temperature change between present and the last glacial maximum, TC; (g) precipitation change between present and the last glacial maximum, PC; (h) population, POP; (i) area of anthropogenic land use, AALU; (j) species richness, SR. 

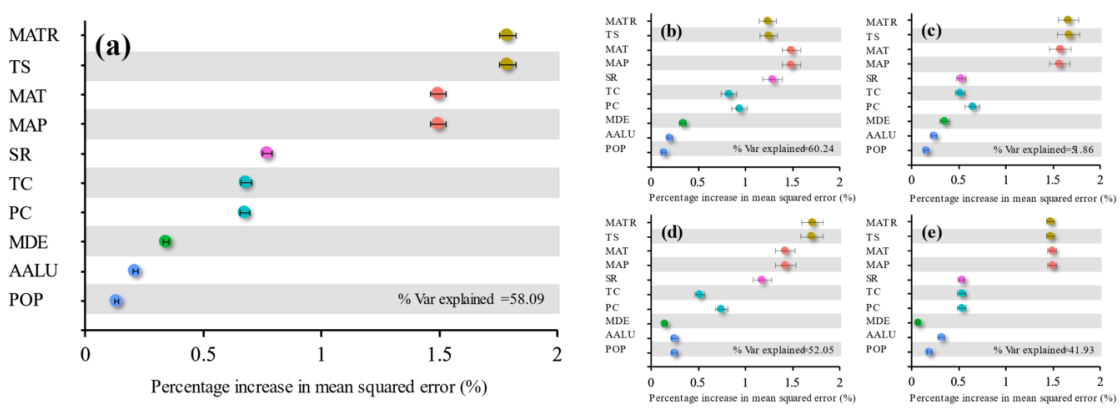

Fig. 5 The average of percentage increase in mean squared error of each environmental variable in 1000 Random Forest models for (a) overall species, (b) woody species, (c) herbaceous species, (d) temperate species, and (e) tropical species. 